\title{
Riluzole: A neuroprotective drug with potential as a novel anti-cancer agent (Review)
}

\author{
ANGELINA BLYUFER $^{1 *}$, SONAM LHAMO ${ }^{1 *}$, CASSEY TAM $^{1 *}$ IFFAT TARIQ $^{1 *}$, \\ THONGTHAI THAVORNWATANAYONG ${ }^{2}$ and SHAHANA S. MAHAJAN ${ }^{1-4}$ \\ ${ }^{1}$ Department of Medical Laboratory Sciences, Hunter College, City University of New York, New York, NY 10010; \\ ${ }^{2} \mathrm{PhD}$ Program in Biology, ${ }^{3} \mathrm{PhD}$ Program in Biochemistry, The Graduate Center of The City \\ University of New York, New York, NY 10016; ${ }^{4}$ Brain Mind Research Institute, \\ Weill Cornell Medical College, New York, NY 10021, USA
}

Received August 26, 2021; Accepted October 11, 2021

DOI: $10.3892 /$ ijo.2021.5275

\begin{abstract}
Riluzole, a glutamate release inhibitor, has been in use for the treatment of amyotrophic lateral sclerosis for over two decades since its approval by the Food and Drug Administration. Recently, riluzole has been evaluated in cancer cells and indicated to block cell proliferation and/or induce cell death. Riluzole has been proven effective as an anti-neoplastic drug in cancers of various tissue origins, including the skin, breast, pancreas, colon, liver, bone, brain, lung and nasopharynx. While cancer cells expressing glutamate receptors frequently respond to riluzole treatment, numerous types of cancer cell lacking glutamate receptors unexpectedly responded to riluzole treatment as well. Riluzole was demonstrated to interfere with glutamate secretion, growth signaling pathways, $\mathrm{Ca}^{2+}$ homeostasis, glutathione synthesis, reactive oxygen species generation and integrity of DNA, as well as autophagic and apoptotic pathways. Of note, riluzole is highly effective in inducing cell death in cisplatin-resistant lung cancer cells. Furthermore, riluzole pretreatment sensitizes glioma and melanoma to radiation therapy. In addition, in triple-negative breast cancer, colorectal cancer, melanoma and glioblastoma, riluzole has synergistic effects in combination with select drugs. In an effort to highlight the therapeutic potential of riluzole, the current study reviewed the effect and outcome of riluzole treatment on numerous cancer types investigated thus far. The mechanism of action and the various molecular pathways affected by riluzole are discussed.
\end{abstract}

Correspondence to: Professor Shahana S. Mahajan, Department of Medical Laboratory Sciences, Hunter College, City University of New York, 425 East, 25th Street, New York, NY 10010, USA

E-mail: smahajan@hunter.cuny.edu

${ }^{*}$ Contributed equally

Key words: riluzole, glutamate secretion and signaling, reactive oxygen species, DNA damage, apoptosis, cell cycle arrest, combination therapy

\section{Contents}

1. Introduction

2. Mechanisms of action of riluzole

3. Riluzole in cancer treatment

4. Conclusion

\section{Introduction}

The drug riluzole [2-amino 6 (trifluoromethoxy)benzothiazole], due to its neuroprotective qualities, was Food and Drug Administration-approved in 1995 for the treatment and management of amyotrophic lateral sclerosis (1). Riluzole was indicated to block voltage-dependent sodium channels in a dose-dependent manner $(2,3)$. While the precise mechanism of action of riluzole is still under investigation, numerous studies have demonstrated that the effect of riluzole is derived from its ability to block glutamate release and enhance glutamate reuptake (4), thus leading to the inhibition of glutamate-dependent signaling. Glutamate signaling is hyperactive in numerous neurological diseases in which riluzole may have beneficial effects (5). Of note, cancers of numerous tissues also rely on glutamate signaling to survive and proliferate (6). Consequently, several investigations have explored the efficacy of riluzole treatment in different cancers types, both in vitro and in vivo (Table I). Due to its efficacy, low toxicity and tolerability, riluzole became a potential treatment for a number of cancer types (7-9). Numerous studies have uncovered multiple mechanisms by which riluzole targets each specific cell type. An understanding of the molecular targets of riluzole and underlying mechanism in specific cancer types may improve the current application of riluzole in cancer treatment. The present review focused on all available data pertaining to the effects of riluzole in cancers of various tissue origins and its potential as a therapeutic agent, as represented in Fig. 1.

\section{Mechanisms of action of riluzole}

Consequences of blocking glutamate secretion with riluzole. Glutamate signaling is frequently mentioned in the context of 
the central nervous system, where it acts as the major excitatory neurotransmitter; however, glutamate signaling is operational in numerous different cell types (10). For instance, there is a strong link between glutamate signaling, cell survival and differentiation of peripheral tissues, including bone (10-12). The key receptors in the glutamate pathway are classified into two broad categories: Ionotropic glutamate receptors and metabotropic-glutamate receptors (mGluR/GRM) $(5,13)$. While the glutamate receptors largely differ in structure and mechanism of action, these receptors frequently share similar functions and interact with each other in a cooperative or non-cooperative manner (14). Ionotropic glutamate receptors are involved in the regulation of ion intake, including certain essential ions such as $\mathrm{Ca}^{2+}$, which is responsible for maintaining cellular homeostasis. The metabotropic glutamate receptors are $\mathrm{G}$ protein-coupled receptors, which mediate signal transduction pathways involved in several cellular processes, such as cell stress response, survival, growth and proliferation (5).

Cystine-glutamate antiporter (xCT) is a glutamate cystine antiporter that regulates the antioxidant system in cells that contributes to growth, metastasis and invasion of cancer cells (15). In this context, cancer cell lines of multiple tissue origin have been indicated to secrete glutamate via the xCT transporter $(16,17)$. Of note, gliomas increase glutamate levels in the extracellular space by mislocalized excitatory amino acid transporter 1 (EAAT1) to the nucleus and decreasing the levels of EAAT2, while simultaneously increasing glutamate secretion via the $\mathrm{xCT}$ transporter (18). Excessive secretion of glutamate by glioma causes neurotoxicity to facilitate glioma growth (19). The silencing of the xCT by small interfering RNA in glioma decreased glutamate secretion, neurodegeneration and brain edema (20). Of note, riluzole induced cytotoxicity in GRM3-expressing glioma in vitro and reduced tumor size in xenograft mice (7). In melanoma, riluzole dose-dependently decreased cell proliferation in vitro. It is noteworthy that downregulation of the $\mathrm{xCT}$ was observed in xenograft-bearing animals that were treated with riluzole, suggesting that $\mathrm{xCT}$ is a possible molecular target of riluzole (21). Another remarkable study suggested riluzole's growth inhibitory effect on cisplatin-resistant small cell lung cancer cells in vitro via the upregulation of both the $\mathrm{xCT}$ and CD44 variant, of which CD44 is known to stabilize $\mathrm{xCT}$ (22). Although riluzole reduced tumor size in vivo, the effects of riluzole were indicated to be independent of glutamate signaling (22). Thus, blocking xCT and subsequent inhibition of glutamate receptors may be one of the mechanisms by which riluzole prevents cell growth.

Riluzole modulates glutamate-dependent and glutamateindependent intracellular signaling pathways. In numerous cancer cell types, glutamate receptors are overexpressed to enhance cancer cell survival and proliferation (9). Tumorigenesis is linked to several major intracellular signaling pathways, including the PI3K/Akt/mTOR, Ras-MAP-ERK and MAPK/ERK pathways (23-26). A genomic study revealed a high frequency of mutations across pathways, suggesting potential broad cancer-targeting strategies (27). For instance, GRM1 is overexpressed in melanoma cells, whereas the GRM3 receptor is expressed in gliomas $(7,28)$. Stimulation of GRM1 in melanomas and GRM3 in glioma cells by agonists leads to the activation of MAPK signaling, more specifically to the phosphorylation of ERK $(7,28)$. In malignant melanoma, GRM3 is mutated, resulting in hypersensitivity of the MEK-MAPK pathway, and overexpression of GRM5 increased the activation of the MAPK pathway $(29,30)$. In melanoma, treatment with riluzole effectively suppressed MAPK/ERK and PI3K/AKT pathway hyperactivity and related cellular processes, including cell proliferation in vitro, as well as in a phase 0 clinical trial $(28,31)$. While the efficacy of riluzole was observed in melanoma, it appears that the presence of mutations in N-Ras, B-Raf or phosphatase and tensin homolog (PTEN) was able to hinder the effect of the drug $(31,32)$. Of note, riluzole in combination with a drug for mTOR, a downstream effector of PI3K/AKT, improved the effect of riluzole on melanoma cells with these mutations (32).

In human brain tumor-like stem cells (BTSCs) derived from glioblastoma, riluzole inhibited cell growth by decreasing GLUT3 transporter expression. Decreased GLUT3 expression resulted in lower uptake of glucose by the BTSCs, which heavily rely on aerobic glycolysis. Consequently, riluzole-induced decrease in GLUT3 was indicated to depend on the decrease in phosphorylated (p-)AKT, leading to a decrease in the induction of hypoxia-inducible factor (HIF) $1 \alpha$ expression (33). HIF1 $\alpha$ is a transcriptional regulator of the SLC2A3 gene, which encodes for GLUT3 glucose transporter. Therefore, riluzole modulates metabolic activity of cells by altering phosphorylation of AKT. Of note, poor prognosis of glioblastoma is dependent on the overexpression of DNA (cytosine-5-)-methyltransferase 1 (DNMT1), which causes hypermethylation of tumor suppressor genes (34). Riluzole was indicated to decrease DNMT1 gene expression as a consequence of decreased GLUT3 expression and reduced tumor size in mice (33). Therefore, riluzole inhibited cell growth by altering AKT phosphorylation to control glucose metabolism in BTSCs and indirectly altering the expression of tumor suppressor genes to inhibit growth in glioblastoma cells. Furthermore, in osteosarcoma expressing GRM5, riluzole blocked cell proliferation by altering phosphorylation of AKT (at both T308 and S473) and p70 S6 kinase at threonine 389, a hallmark of mTOR activation, suggesting the activation of the $\mathrm{PI} 3 \mathrm{~K} / \mathrm{AKT} / \mathrm{mTOR}$ pathway in osteosarcoma growth. In addition, riluzole altered phosphorylation at ERK1/2and JNK1/2 kinases in osteosarcoma (35). Another key pathway linked to oncogenesis is $\mathrm{Wnt} / \beta$-catenin signaling, which regulates the amount of the transcriptional co-activator $\beta$-catenin (36). In malignant melanoma, downregulation of $\beta$-catenin has an important role in disease progression and contributes to poor prognosis (37). Of note, in melanoma, riluzole increased the levels of WNT3A protein involved in the stimulation of the Wnt/ $\beta$-catenin pathway and melanocyte differentiation, subsequently leading to decreased cell proliferation both in vivo and in vitro (38). Thus, riluzole targets multiple signaling pathways to block cell proliferation in glioma, osteosarcoma and melanoma.

Riluzole regulates intracellular $\mathrm{Ca}^{2+}$ in both cancerous and non-cancerous cells. In the endoplasmic reticulum (ER), calcium levels influence protein folding and trafficking, whereas in mitochondria, calcium influences mitochondrial permeability, which contributes to the modulation of 
Table I. Effects of riluzole on cancer cells.

\begin{tabular}{lll}
\hline Cancer type/cell lines & Mechanism (Refs.) \\
\hline
\end{tabular}

Pancreatic cancer

PANC1, SW1990, BXPC3, ASPC1

Colorectal cancer

HCT116, H630, HCT8, CACO2 and HT29

Hepatocellular carcinoma

SNU449, Huh-7

Melanoma

SKMEL2, C8161, UACC903 and 1205Lu

Prostate cancer

LNCaP-androgen-dependent

C4-2-androgen-independent

22Rv 1

$\mathrm{VCaP}$

CWR1-R1ca

Breast cancer

SUM149

SUM102

SUM229

Glioblastoma

LN229, T98G, short term PDX patient-derived line

GBM6

U87MG glioblastoma

Neuroblastoma

Neuron-neuroblastoma hybrid (NSC-34D), IM32 neuroblastoma cells Calcium levels

Lung cancer

A549

Glioma

U87MG glioma cells, U118MG \& LN229

Brain tumor stem-like cell lines used: 11SP and 64SP

C6 cells

Human nasopharyngeal carcinoma

CNE1, CNE2 and HNE1

Osteosarcoma

LM7 and OS482

LM7
Autophagy

G2/M cell cycle arrest

Apoptosis

Sensitizes cells to cisplatin

reduces cell viability in vitro and polyp

development in vivo

$\mathrm{G} 2 / \mathrm{M}$ arrest, apoptosis

G2/M cell cycle arrest

Apoptosis

G2/M cell cycle arrest

MAPK/PI3K/AKT signaling

DNA damage

Apoptosis

ER stress

Autophagy

Apoptosis

Apoptosis

ER stress

Translational control

G2/M arrest, apoptosis

Cytotoxicity, tumor suppression, DNA damage

Autophagy

Sensitizes to radiation

G2/M arrest, apoptosis

ATM/P53

G2/M arrest

Sensitizes to radiation

Inhibits cell proliferation

Apoptosis

cAbl kinase activation

YAP phosphorylation at Y357, binding to $\mathrm{p} 73$ and Bax promoter activation

ER, endoplasmic reticulum; YAP, YES-associated protein. 


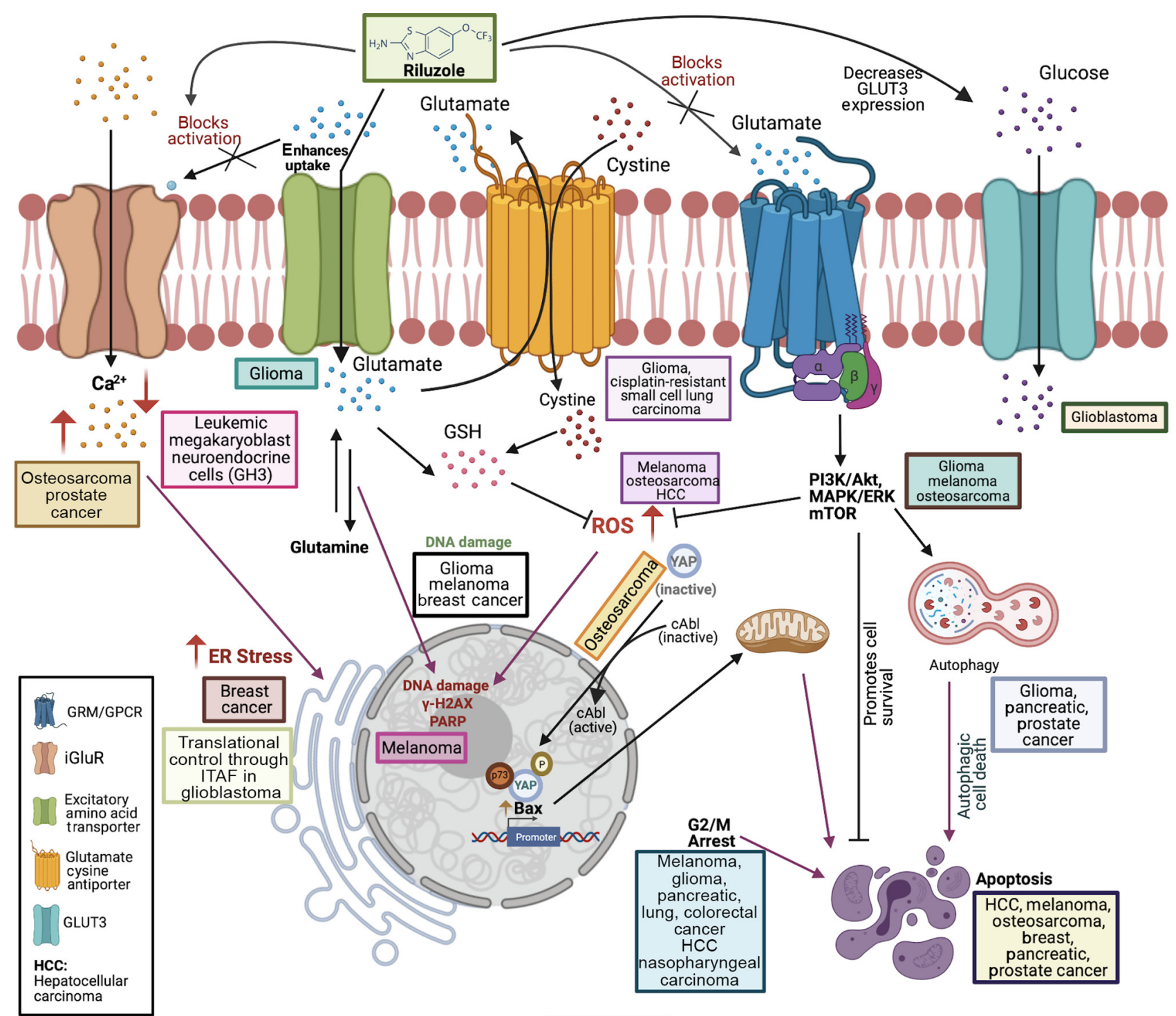

Figure 1. Schematic representation of receptors and pathways targeted by riluzole. Riluzole was indicated to increase $\mathrm{Ca}^{2+}$ levels in osteosarcoma and prostate cancer, while decreasing $\mathrm{Ca}^{2+}$ levels in leukemic megakaryoblast neuroendocrine cells (GH3). Increased $\mathrm{Ca}^{2+}$ levels contribute to ER stress, as observed in breast cancer. Riluzole is known to block protein translation in glioblastoma through ITAF, IRES trans-acting factor. Riluzole is thought to inhibit glutamate release by blocking the voltage-dependent sodium channels (not shown) and enhances glutamate uptake through excitatory amino acid transporter, which regulates extracellular glutamate levels. Glioma cells lack a functional glutamate uptake system, leading to excessive extracellular glutamate. Riluzole blocks glutamate cystine antiporter in glioma and cisplatin-resistant small cell lung carcinoma. Inhibition of glutamate cystine antiporter by riluzole reduces cystine import, thereby decreasing GSH synthesis, which in turn leads to increase in ROS, as observed in melanoma, osteosarcoma and HCC. Increases in ROS lead to DNA damage as reported in glioma, melanoma and breast cancer. In melanoma cells, riluzole elevates $\gamma$-H2AX levels and increases PARP cleavage. DNA damage caused by riluzole leads to cell cycle arrest in G2/M phase, as observed in melanoma, pancreatic cancer, HCC and nasopharyngeal carcinoma. Increased ROS may contribute to phosphorylation of YAP by cAbl kinase to promote apoptosis in osteosarcoma. Inhibition of glutamate release by riluzole prevents activation of GRM and signaling through these receptors, as reported in glioma, melanoma and osteosarcoma. Blockage of these pathways by riluzole induces autophagic death in glioma, pancreatic cancer and prostate cancer. Riluzole induces apoptosis in breast cancer, melanoma, HCC, prostate cancer, pancreatic cancer and osteosarcoma. Riluzole was also indicated to decrease glucose transporter GLUT3 levels, thereby decreasing glucose import in glioblastoma. Thus, riluzole targets numerous types of receptors/transporters and associated signaling pathways to cause cell death in various cancer types. The figure was rendered using Biorender.com. ROS, reactive oxygen species; HCC, hepatocellular carcinoma; ER, endoplasmic reticulum; GSH, glutathione; GRM, metabotropic glutamate receptors; GPCR, G protein-coupled receptor; YAP, YES-associated protein; PARP, poly (adenosine diphosphate ribose) polymerase; iGluR, ionotropic glutamate receptors; ITAF, IRES trans-acting factor.

intracellular reactive oxygen species (ROS) levels and may have a direct effect on mitochondrial-mediated apoptosis inside the cell (39). Although riluzole is known to inhibit glutamate release and hence block glutamate signaling, certain studies reported its potential for targeting $\mathrm{Ca}^{2+}$ signaling in cells. In one of these studies, riluzole inhibited spontaneous $\mathrm{Ca}^{2+}$ signaling in the immortalized growth hormone-secreting pituitary cell line GH3 (40). In another study using the neuroblastoma-spinal motor neuron fusion cell line NSC-34D (non-cancerous), riluzole counteracted the upregulation of $\mathrm{Ca}^{2+}$ increase and cell death induced by thapsigargin, a known inhibitor of sarcoplasmic calcium ATPase (41). While the exact mechanism for $\mathrm{Ca}^{2+}$ inhibition by riluzole still remains to be determined in cancer cells, riluzole was reported to block glutamate release and glutamate regulated $\mathrm{Ca}^{2+}$ entry in leukemic megakaryoblasts and promoted differentiation by 
blocking cell proliferation (42). Contrary to this effect, riluzole increased cytosolic $\mathrm{Ca}^{2+}$ increase in prostate cancer cells that increased ER stress, and increased $\mathrm{Ca}^{2+}$ levels in MG63 osteosarcoma cells through an unidentified pathway $(43,44)$. These results suggested that intracellular $\mathrm{Ca}^{2+}$ regulation is one of the cellular processes in cancer that may be affected by riluzole.

Riluzole increases oxidative stress. Typically, the cell is thought to be under oxidative stress when the intracellular levels of reactive oxygen species (ROS), such as hydrogen peroxide $\left(\mathrm{H}_{2} \mathrm{O}_{2}\right)$ and ion species $\left(\mathrm{O}_{2}^{-}, \mathrm{OH}\right)$, exceed the levels of antioxidants. Tumor cells have comparatively higher metabolic requirements and altered metabolism; consequently, they generate increased ROS, which are employed by the cells for survival, cell motility and metastasis, tumor progression and angiogenesis $(45,46)$. Glutathione $(\mathrm{GSH})$ is a well-known antioxidant that reduces oxidative stress and ROS levels by accepting an electron from a free radical on ROS (47). Of note, GSH synthesis is directly linked to glutamate release, since glutamate serves as one of the precursor molecules of GSH (48). In normal cells, the overload of intracellular glutamate and upregulation of $\mathrm{Ca}^{2+}$ leads to increases in ROS and ER stress, resulting in both DNA damage and subsequent apoptosis (49). On the other hand, cancer cells have a number of mechanisms in place to resist apoptosis. The antioxidant production pathways are typically upregulated, which include GSH synthesis and salvage pathways $(50,51)$. A key player in GSH production is $\mathrm{xCT}$, which imports cystine for GSH synthesis and is overexpressed in cancer (15).

By inhibiting glutamate release in cancer cells, riluzole has been indicated to decrease the overall GSH levels (22). The reduction in GSH leads to a marked reduction in antioxidants and increased ROS, which induces cell cycle arrest in $\mathrm{G} 2 / \mathrm{M}$ phase and eventual apoptosis $(7,22,52,53)$. In one of the most recent studies on DNA damage repair inhibition in melanoma, riluzole promoted the accumulation of ROS that triggered DNA double-strand breaks (54). However, this effect was observed in both GluR1-positive and -negative melanoma cells, which further added to the complexity of the mechanisms of riluzole causing oxidative stress (54). Of note, in hepatocellular carcinoma (HCC), riluzole treatment was indicated to cause an increase in cellular glutamate content, which led to a decrease in GSH production as a consequence of a decrease in cysteine uptake by the cells. This further resulted in the accumulation of ROS, leading to apoptosis. In addition, administration of riluzole inhibited growth in HCC xenografts, and reduced GSH and increased ROS levels in the tumors (52). In osteosarcoma, riluzole increased ROS production, leading to the activation of cAbl kinase, which participates in events leading to apoptosis (55). Of note, the increased ROS in cisplatin-resistant lung cancer cells were further enhanced by riluzole to induce cell death, making it the only agent so far to successfully kill cisplatin-resistant cells (22). It is noteworthy that in cancer cells where glutamate secretion occurs via $\mathrm{xCT}$, riluzole may increase intracellular levels of glutamate to cause glutamate-induced oxidative stress while simultaneously blocking GSH synthesis due to deficiency of cystine by blocking XCT (21). While the mechanism remains to be fully elucidated, the available studies suggested that in numerous cancer types, glutamate release inhibition by riluzole contributes to ROS production.

Riluzole and protein translation. In glioblastoma, inhibitors of mTOR kinase have been indicated to enhance IRES-dependent protein synthesis of key regulators of the cell cycle, leading to resistance to the mTOR inhibitors. Furthermore, IRES-dependent translation was reported to have a key role in tumor growth and resistance. One of the significant proteins involved in response to the accumulation of misfolded protein is IRES trans-acting factor (ITAF) heterogenous nuclear ribonucleoprotein A1 (hnRNP A1). hnRNA A1 has been indicated to regulate IRES-dependent translation of c-myc and cyclin D1 genes (56). In a recent study using surface plasmon resonance imaging, riluzole was indicated to directly bind to hnRNP A1 through its specific binding site to prevent IRES RNA binding. This was the first report to demonstrate the interaction of riluzole with a protein directly to regulate its activity (57). In a recent study, riluzole was indicated to downregulate ITAF hnRNP A1 activity to decrease translation of c-myc and cyclin D1 genes, and as a result, to assist in offsetting the resistance to mTOR inhibitor in glioblastoma (57). Thus, riluzole may exert its effect through direct interactions with proteins outside of the glutamate metabolic and signaling pathway, such as ITAF hnRNP A1.

Riluzole induces DNA damage. A cell may be able to sustain DNA damage from intracellular factors such as oxidative stress and replication errors to extracellular factors such as ultraviolet radiation and chemical carcinogens (58). There are two prominent classifications of DNA damage: Single-strand breaks (SSBs) and double-strand breaks (DSBs) (59). It is well known that cells have adopted several strategies to repair DNA damage; for instance, SSBs are repaired through a base excision repair pathway, whereas for DSBs, the homologous recombination repair or the non-homologous end-joining pathways are utilized. Damages that arise at a particular nucleotide also have specialized repair mechanisms, such as the nucleotide excision repair and mismatch repair pathways. Cell cycle checkpoints serve as a protective mechanism against DNA damage. Together, these pathways comprise the cellular DNA damage response (DDR) $(59,60)$. Dysregulation of DDR is a common finding in various cancers and is typically associated with mutations of specific proteins in a given pathway. For instance, mutation in p53 allows the damaged cell to pass the cell cycle checkpoint and proliferate despite not satisfying the checkpoint requirements. Cells with DDR defects frequently become desensitized to radiation and chemotherapy (59).

Multiple lines of evidence suggest that riluzole causes damaged cells to accumulate at cell cycle checkpoints, eventually triggering apoptosis. Specifically, riluzole treatment in glioma and melanoma cells produce increased levels of DDR proteins, such as poly(adenosine diphosphate ribose) polymerase (PARP) and H2AX $(7,53)$. These two biomarkers are frequently used to assess drug efficacy, since both are frequently present when DNA is damaged. The DSBs are known to induce the phosphorylation of histone H2AX, while PARP cleavage is associated with activation of SSB repair (59). Furthermore, the accumulation of DNA damage is also associated with a reduction in glutamate release and GSH levels, 
suggesting that the production of ROS stimulated by riluzole treatment is the main contributor to the DNA damage in these cancer cells (7,53). A similar increase in phosphorylation of H2AX was also observed in a phase II clinical trial for advanced melanoma (61). These studies strongly suggest that riluzole may cause DNA damage, most likely due to induction of ROS in cancer cells.

Riluzole causes $62 / M$ cell cycle arrest. In numerous studies, riluzole has been indicated to cause $\mathrm{G} 2 / \mathrm{M}$ cell cycle arrest in cancer cells. For instance, the HCC cell lines SNU 449 and Huh-7 exhibited cell cycle arrest in G2/M phase upon exposure to riluzole. Riluzole was indicated to elevate the expression of cyclin B1 and depress the expression of p21 and p-cdc2, leading to $\mathrm{G} 2 / \mathrm{M}$ cell cycle inhibition in these cells (35). Riluzole also induced G2/M phase arrest in the pancreatic cancer cell lines PANC1 and ASPC1 in a dose-dependent manner, while concomitantly decreasing the levels of the regulatory protein cyclin-dependent kinase 1 (40). In an in vivo brain metastasis study using GRM1-expressing human melanoma cells, riluzole caused G2/M phase arrest and DNA damage. In addition, Riluzole increased radiosensitivity, resulting in enhanced DNA damage and reduced metastases in an animal model (62). Riluzole also induced cell cycle arrest in A549 cells (lung cancer), as well as glioma and colorectal adenocarcinoma cells (63). Furthermore, in studies involving human nasopharyngeal carcinoma, Riluzole induced G2/M arrest and apoptosis (64). In summary, these studies provide evidence that riluzole causes cell cycle arrest in G2/M phase in HCC, pancreatic cancer, melanoma and nasopharyngeal carcinoma cells.

Autophagy. Autophagy, also known as 'self-digestion', is a process of elimination of misfolded proteins and damaged organelles. It is characterized by the autophagosome formation around the components and the fusion of autophagosome with the lysosome for degradation (65). Of note, intracellular calcium and ROS levels are also implicated in autophagy regulation. In normal cells, basal regulation of autophagy contributes to homeostasis; however, in cancer, autophagy dysregulation is linked to uncontrolled cell growth and proliferation, making it a desirable target for cancer therapy $(65,66)$. As observed in pancreatic cell lines, riluzole resulted in the upregulation of an autophagy substrate, p62, as well as cell death in a dose-dependent manner (67). In another study using a castrate-resistant prostate cancer cell line expressing GRM1, riluzole upregulated intracellular $\mathrm{Ca}^{2+}$ levels and increased the expression of autophagy markers such as Beclin 1, LC3AII (microtubule associated protein1 light chain 3AII) and p62, leading to autophagy-mediated degradation of androgen receptor (44). Furthermore, in glioma, riluzole caused downregulation of PI3K/Akt signaling and GLUT3 expression, which led to autophagic cell death (33). Together, these studies indicated that riluzole interferes with autophagic pathways to induce cell death in various cancers types.

Riluzole induces apoptosis. Typically, upregulated PI3K/Akt and MAPK/ERK pathways contribute to cancer survival via activated Akt, mTOR, ERK, Ras and Braf proteins that downregulate pro-apoptotic proteins while activating anti-apoptotic proteins. Apoptosis is induced via the intrinsic apoptotic pathway or externally by ligand binding to the cell receptor via the extrinsic apoptotic pathway (68). Both pathways include sequential caspase cleavage, with slight differences in caspases involved in the process. The intrinsic apoptotic pathway is generally triggered in cells under oxidative stress or when DNA sustains serious unrepairable damage. The process is regulated by pro-apoptotic proteins such as Bax and Bak, and anti-apoptotic proteins like Bcl-2 and Bcl-xl. When the apoptotic processes are initiated, the apoptosome is formed, which is made up of Apaf-1 and cytochrome $c$ (released from mitochondria), as well as pro-caspase-9. The formation of this complex then cleaves and activates caspase 9 to further activate downstream caspases (caspases3/6/7) to induce apoptotic cell death (68). In cancer cells, aberrant downregulation of apoptotic proteins and inhibition of apoptosis is common.

In certain studies on melanoma, $\mathrm{HCC}$, pancreatic cancer, prostate cancer and breast cancer, riluzole treatment was indicated to induce apoptotic cell death by alteration of different cellular processes, ranging from oxidative stress induction, autophagy inhibition, and downregulation of survival intracellular signaling pathways $(7,52,67,69)$. In a number of these studies, apoptosis was assessed by detecting caspase- 3 and caspase-9 levels, which are common apoptotic markers. In HCC, cleaved caspase-3 and -9, as well as PARP, were increased with riluzole treatment (52). Similarly, pancreatic cancer cells also exhibited an increase in caspase-3 (67). Furthermore, in melanomas, both GRM1-positive and GRM1-negative, an increased amount of cleaved PARP and caspase- 3 was observed following treatment with riluzole and radiation (70). In prostate cancer cells lines, independent of their androgen-dependent status, riluzole decreased cell viability by activation of caspase-3, -8 and -9 (71). In addition, riluzole was also indicated to induce apoptosis following cell cycle arrest via the activation of the ATM/p53 pathway in nasopharyngeal carcinoma (64). A recent study by our group suggested that in osteosarcoma, riluzole activated c-Abl kinase, which is typically activated during DNA damage response. Activated c-Abl kinase was indicated to phosphorylate YES-associated protein (60), a transcription coactivator, to facilitate its interaction with P73, a homolog of P53. Riluzole-mediated YAP and P73 complex was reported to activate Bax promoter to regulate pro-apoptotic activity (55). Previous studies by our group also suggested that iron oxide nanoparticle-delivered riluzole induced apoptosis in vitro in osteosarcoma cells and shrunk osteosarcoma tumors in a xenograft mouse model $(72,73)$. Since apoptosis ultimately leads to the elimination of cancer cells, a better understanding of the induction of riluzole-mediated cell death, the effects of riluzole on different cellular processes and how they are related to apoptosis may further improve the use of riluzole in different cancer types.

\section{Riluzole in cancer treatment}

Mono- and combined therapy. A better understanding of cancer biology, particularly the regulation of key factors and processes fueling cell growth and metastasis, will bring advancements in cancer treatment. Cancer cells are known to harbor multiple mutations across different pathways to promote cell proliferation and metastasis (74). While monotherapy with single drugs 
Table II. Combination therapy with riluzole.

\begin{tabular}{|c|c|c|c|c|c|}
\hline Subjects/samples & Cancer type & $\begin{array}{l}\text { Therapeutic } \\
\text { agents } \\
\text { combined } \\
\text { with riluzole }\end{array}$ & Mechanism & $\begin{array}{l}\text { Observed effects with } \\
\text { riluzole }\end{array}$ & (Refs.) \\
\hline $\begin{array}{l}\text { Primary HCC from } \\
4 \text { patients }\end{array}$ & $\mathrm{HCC}$ & Sorafenib & $\begin{array}{l}\text { Multikinase inhibitor targets } \\
\text { angiogenesis (Raf-1, b-Raf) } \\
\text { target proliferation (VEGF, } \\
\text { PDGFB receptors) }\end{array}$ & $\begin{array}{l}\text { Additive effect on cell } \\
\text { growth inhibition }\end{array}$ & $(52)$ \\
\hline $\begin{array}{l}\text { MDA-MB-231, } \\
\text { SUM149, SUM229 } \\
\text { in vitro and in xenograft }\end{array}$ & $\begin{array}{l}\text { Triple-negative } \\
\text { breast cancer }\end{array}$ & Paclitaxel & $\begin{array}{l}\text { Inhibitor of tubulin, } \\
\text { inhibit mitotic spindle } \\
\text { assembly involved in } \\
\text { chromosome segregation } \\
\text { and cell division, induced } \\
\text { apoptosis }\end{array}$ & $\begin{array}{l}\text { Synergistic cell growth } \\
\text { inhibition, } \\
\text { induced apoptosis }\end{array}$ & (79) \\
\hline $\begin{array}{l}\text { HCT116 } \\
\text { with knocked down } \\
\text { hERG expression }\end{array}$ & $\begin{array}{l}\text { Colorectal } \\
\text { cancer }\end{array}$ & Cisplatin & $\begin{array}{l}\text { Binds to DNA and inhibits } \\
\text { replication, promotes DNA } \\
\text { damage, } \\
\text { inhibits mitosis }\end{array}$ & $\begin{array}{l}\text { Synergistic effect in } \\
\text { reduced viability of } \\
\text { cisplatin-resistant } \\
\text { cells due to hERG1 } \\
\text { overexpression }\end{array}$ & $(77)$ \\
\hline $\mathrm{TREK}^{+/+} / \mathrm{C} 7 / \mathrm{BL} 6$ mice & $\begin{array}{l}\text { Not } \\
\text { cancerous }\end{array}$ & Oxaliplatin & $\begin{array}{l}\text { Inhibits DNA synthesis, DNA } \\
\text { replication and transcription, } \\
\text { induces apoptosis. } \\
\text { Neurotoxic side effects } \\
\text { (elevated glutamate release) }\end{array}$ & $\begin{array}{l}\text { Reduced neurotoxic side } \\
\text { effects due to TREK-1 } \\
\text { potassium channel }\end{array}$ & $(92)$ \\
\hline $\begin{array}{l}\text { Melanoma cell lines for } \\
\text { In vitro C8161 (WT } \\
\text { BRAF \& NRAS), } \\
\text { UACC903 } \\
\text { UACC930, } \\
\text { HT144 (BRAF \& PTEN mt) } \\
\text { SKMEL2 (NRAS mt) } \\
\text { For in vivo C8161 } \\
\text { UACC903 } \\
\text { All cell lines are GRM1- } \\
\text { positive except UACC930 }\end{array}$ & Melanoma & Rapamycin & $\begin{array}{l}\text { mTOR inhibitor } \\
\text { Combination therapy was } \\
\text { more effective than with } \\
\text { individual agent }\end{array}$ & $\begin{array}{l}\text { Decreased anchorage- } \\
\text { independent growth and } \\
\text { tumor growth in xenograft. } \\
\text { Combination therapy } \\
\text { effective regardless of } \\
\text { BRAF mutation and PI }\end{array}$ & (32) \\
\hline $\begin{array}{l}\text { Melanoma cell line } \\
\text { expressing GRM1: } \\
\text { UAC } 903,1205 \mathrm{Lu}, \mathrm{C} 8161 \\
\text { with either B-RAF WT or mt, } \\
\text { in vitro and xenograft }\end{array}$ & Melanoma & Sorafenib & $\begin{array}{l}\text { Multikinase inhibitor targets } \\
\text { angiogenesis (Raf-1, b-Raf) } \\
\text { target proliferation (VEGF, } \\
\text { PDGFB receptors) }\end{array}$ & $\begin{array}{l}\text { Synergistic effect Reduced } \\
\text { PI3K/Akt signaling, } \\
\text { reduced cell proliferation } \\
\text { on C8161, additive effect } \\
\text { on UAC903 and } 1205 \mathrm{Lu}\end{array}$ & $(78)$ \\
\hline $\begin{array}{l}\text { Melanoma cell line } \\
\text { expressing GRM1: UAC903, } \\
\text { 1205Lu, C8161 with either } \\
\text { B-RAF WT or mt, } \\
\text { In vitro and xenograft }\end{array}$ & Melanoma & PLX4720 & Inhibit B-RafV600E & $\begin{array}{l}\text { Synergistic effect } \\
\text { but less efficacy } \\
\text { compares to with sorafenib }\end{array}$ & (78) \\
\hline $\begin{array}{l}\text { Intracranially injected } \\
\text { melanoma C8161-luc }\end{array}$ & Melanoma & Radiation & Increased apoptosis & $\begin{array}{l}\text { Enhanced the effect of } \\
\text { radiation }\end{array}$ & $(62)$ \\
\hline $\begin{array}{l}\text { GRM3 expressing cell } \\
\text { line U87, and T98G } \\
\text { cell line, patients' } \\
\text { primary samples } \\
\text { with detectable } \\
\text { GRM3 expression }\end{array}$ & Glioma & Radiation & $\begin{array}{l}\text { ROS, DNA damage, } \\
\text { apoptosis }\end{array}$ & $\begin{array}{l}\text { Enhanced ROS } \\
\text { accumulation, } \\
\text { reduced PI3K/Akt and } \\
\text { MAPK/ERK signaling } \\
\text { and DNA damage and } \\
\text { apoptosis induction }\end{array}$ & (7) \\
\hline
\end{tabular}


Table II. Continued.

\begin{tabular}{|c|c|c|c|c|c|}
\hline Subjects/samples & Cancer type & $\begin{array}{l}\text { Therapeutic } \\
\text { agents } \\
\text { combined } \\
\text { with riluzole }\end{array}$ & Mechanism & $\begin{array}{l}\text { Observed effects with } \\
\text { riluzole }\end{array}$ & (Refs.) \\
\hline LN229 and T98G cell lines & Glioblastoma & pp242 & mTOR inhibitor & $\begin{array}{l}\text { Synergistic effect on } \\
\text { proliferation inhibition, } \\
\text { enhanced cell cycle } \\
\text { arrest and apoptosis induction }\end{array}$ & (57) \\
\hline T98G and UG87 & Glioblastoma & TMZ & $\begin{array}{l}\text { TMZ-induced } \mathrm{O}^{6}- \\
\text { methylguanine DNA } \\
\text { methyltransferase } \\
\text { (MGMT expression) }\end{array}$ & $\begin{array}{l}\text { Synergistic effect in } \\
\text { T98G cells but not UG87 } \\
\text { Suppressed intracranial } \\
\text { tumor growth }\end{array}$ & (93) \\
\hline LM7 & Osteosarcoma & $\begin{array}{l}\text { Iron oxide } \\
\text { nanocage }\end{array}$ & Apoptosis & $\begin{array}{l}\text { Iron oxide nanocage-delivered } \\
\text { riluzole was most effective on } \\
\text { inducing apoptosis both } \\
\text { in vitro and in vivo }\end{array}$ & $(72,73)$ \\
\hline
\end{tabular}

HCC, hepatocellular carcinoma; TMZ, temozolomide; ROS, reactive oxygen species; WT, wild-type; mt, mutant type; GRM1, metabotropic glutamate receptor 1; ERG1, ether-a-go-go-related 1 ion channel; PDGFB, platelet-derived growth factor B; NRAS, neuroblastoma RAS; B-RAF, B-raf proto-oncogene; PTEN, phosphatase and tensin-like protein.

is still in use, it is slowly being replaced by newer and more efficient combinatorial treatments. In addition to traditional radiation and chemotherapy, newer advanced methods of cancer treatment are gaining momentum. Immunotherapy, nanoparticles and gene therapy using the CRISPR/Cas9 (clustered regularly interspaced short palindromic repeats and CRISPR-associated protein 9) gene editing system are among the most promising $(75,76)$. According to studies by our group, when delivered via iron oxide nanocage particles, riluzole caused the highest reduction in osteosarcoma tumor size in nude mouse xenografts $(72,73)$.

In keeping with its promising potency and efficacy, riluzole is being tested in combination with other drugs to enhance its actions. Riluzole is frequently observed to have synergistic effects with other drugs to decrease cell proliferation and viability while also promoting apoptosis. Select drug combinations may amplify these effects in different cancer cell lines. For instance, riluzole in combination with paclitaxel in triple-negative breast cancer, or cisplatin in colorectal cancer, or sorafenib in melanoma, was demonstrated to have synergistic effects (77-79). Combinatorial treatment with riluzole and GRM3 antagonist LY341495 blocked the MAPK signaling pathway in glioma, sensitized glioma to radiation and decreased anchorage-independent colony growth (7). In an in vivo study in mice with intracranially injected melanoma cells, combinatorial treatment led to a significant decrease in tumor volume (62). In melanoma, a combination of sorafenib with riluzole was tested in comparison to another potent inhibitor, PLX4720, with riluzole. While both combinations had synergistic effects, the inhibitory effects of sorafenib and riluzole on cell proliferation were the strongest (78). In HCC, riluzole with sorafenib had an additive effect in decreasing cell proliferation (52). Melanomas harboring PTEN and NRAS mutations exhibit resistance to the action of riluzole after prolonged treatment (19). Of note, riluzole in combination with mTOR or AKT inhibitors had promising results in vitro and in xenograft studies in melanoma with these mutations, and in glioblastoma $(32,57)$. Table II provides a summary of noteworthy experiments that include riluzole in combination with other drugs. While the majority of these studies are limited and confined to animal experiments at the most, they may provide information on mechanisms of action of riluzole or possibly lead to clinical trials in the future.

Riluzole as a radiosensitizer. Aside from using riluzole in combination with other drugs, it may be used as a radiosensitizer to produce favorable effects against cancer. The use of riluzole and radiation therapy revealed a synergistic effect in vitro and in vivo in both melanoma and glioma cell lines $(7,70)$. Malignant melanomas, which typically metastasize into the lungs and brain, are particularly dangerous. Despite several scientific advancements, the prognosis for advanced-stage melanoma patients remains bleak. According to the American Cancer Society, the 5-year relative survival rate for metastatic melanoma patients is only $27 \%$ and these tumors are frequently resistant to chemotherapy and radiation treatment, which makes them even more dangerous and prone to reoccurrence. In an in vivo study in mice injected intracranially with melanoma cells, riluzole in combination with radiation led to a significant decrease in tumor volume and GRM1-expressing melanoma exhibited increased apoptosis (62). In another in vitro study on BTSCs, a lower dose of riluzole in combination with radiation therapy unexpectedly resulted in enhanced growth inhibition compared to a higher dose of the drug (33). However, a higher dose of riluzole with radiation therapy proved to be more effective in vivo (33). In addition, riluzole sensitized human nasopharyngeal carcinoma 
cells to radiation through the ATM/P53 signaling pathway and cytotoxicity was enhanced compared to groups treated with riluzole alone both in vivo and in vitro (64).

Toxicity and adverse effects of riluzole. Riluzole was observed to have low toxicity in patients with amyotrophic lateral sclerosis (ALS) treated with a daily oral dose of $\sim 50 \mathrm{mg}$ (80). The area under the curve for the serum concentration at $24 \mathrm{~h}$ was $\sim 2,000 \mathrm{ng} / \mathrm{ml}(81,82)$. Riluzole is well tolerated, with the most common adverse effect observed being headache (83). Other significant side effects were nausea, vertigo, somnolence and asthenia, which were indicated to be dose-related $(84,85)$. Elevation of alanine aminotransferase was also commonly observed in patients (86). Rare and less frequently reported side effects are acute hepatitis, leukopenia and methemoglobinemia (87). Much rarer cases of hypersensitivity pneumonitis and multi-organ autoimmune syndrome were also reported (88). More recently, interstitial pneumonia was observed in $21 \%$ of 92 patients enrolled (89). In patients with ALS, riluzole prolonged tracheostomy-free survival by 3-6 months; however, the long-term toxicity of riluzole requires to be determined for cancer patients considering their longer survival expectancy. In a study performed in Europe and North America, riluzole was reported to be well-tolerated for up to 7 years (90). Further studies require to be performed to assess the long-term tolerability and side effects of riluzole.

Limitations of riluzole. In breast cancer cells, riluzole-induced DNA damage is independent of mGluR1 expression or ER status $(8,91)$. Of note, riluzole-induced DNA damage was not observed in the breast cancer cell line MCF-7, which expresses wild-type P53, whereas other cell lines expressing mutant P53 exhibited riluzole-induced DNA damage (8). On the contrary, in melanoma, riluzole induced DNA damage in an mGluR-dependent manner (53). However, it remains to be determined whether cell line-specific differences in riluzole sensitivity, as observed in breast cancer, are dependent on replicative stress induced by other mutations in cell lines besides mutations in P53 (8). In any particular cancer type, it requires to be determined whether the response to riluzole is dependent on the mutational profile of the cell line, particularly those mutations that predispose the cells to oxidative or replicative stress.

\section{Conclusion}

The current review presents up-to-date information of the mechanisms of action of riluzole. Riluzole has been reported to interfere with diverse cellular processes, such as stress-related response, survival and apoptosis. Various noteworthy studies have demonstrated the cytotoxic effects of riluzole in the following scenarios: i) Cisplatin-resistant lung cancer cells; ii) mTOR inhibitor-resistant glioblastoma; iii) triple-negative breast cancer cells in combination with paclitaxel; iv) sensitizing effect on melanoma, gliomas and nasopharyngeal carcinoma to radiation. Riluzole thus holds great promise for cancers that are challenging to treat effectively. Investigations into the efficacy of riluzole in cancers exhibiting drug resistance may be an effective strategy for circumventing drug resistance in cancer. A deeper insight into the specific mechanisms of riluzole alone and in combination with other drugs in a cell type-dependent manner may improve the efficacy of riluzole and facilitate translation into clinical use.

\section{Acknowledgements}

The authors are grateful for the critical comments provided by Dr Muktar Mahajan (Department of Medical Laboratory Sciences, Hunter College, New York, USA) as well as the careful reviewing of the manuscript by Ms Syeda Maryam Azeem (The Graduate Center, City University of New York, New York, USA) and Ms Shraddha ChandThakuri (Department of Medical Laboratory Sciences, Hunter College, New York, USA). The authors also thank Ms Syeda Maryam Azeem (The Graduate Center, City University of New York, New York, USA) for rendering the schematic representation in Fig. 1 using Biorender.com.

\section{Funding}

The study was funded by the following grants: National Institute of General Medical Sciences, National Institute of Health (grant no. 1 SC1 GM131929-01A1) and the Professional Staff Congress and The City University of New York (grant no. 625040050$)$.

\section{Availability of data and materials}

Data sharing is not applicable to this article, as no datasets were generated or analyzed during the current study.

\section{Authors' contributions}

All authors (AB, SL, CT, IT, TT, SSM) performed literature searches and wrote and edited the article. All authors read and approved the final manuscript. Data authentication is not applicable.

\section{Ethics approval and consent to participate}

Not applicable.

\section{Patient consent for publication}

Not applicable.

\section{Competing interests}

The authors have no competing interests to declare.

\section{References}

1. Doble A: The pharmacology and mechanism of action of riluzole. Neurology 47 (6 Suppl 4): S233-S241, 1996.

2. Urbani A and Belluzzi O: Riluzole inhibits the persistent sodium current in mammalian CNS neurons. Eur J Neurosci 12: 3567-3574, 2000.

3. Zona C, Siniscalchi A, Mercuri NB and Bernardi G: Riluzole interacts with voltage-activated sodium and potassium currents in cultured rat cortical neurons. Neuroscience 85: 931-938, 1998. 
4. Cheah BC, Vucic S, Krishnan AV and Kiernan MC: Riluzole, neuroprotection and amyotrophic lateral sclerosis. Curr Med Chem 17: 1942-1999, 2010.

5. Willard SS and Koochekpour S: Glutamate signaling in benign and malignant disorders: Current status, future perspectives, and therapeutic implications. Int J Biol Sci 9: 728-742, 2013.

6. Yu LJ, Wall BA, Wangari-Talbot J and Chen S: Metabotropic glutamate receptors in cancer. Neuropharmacology 115: 193-202, 2017.

7. Khan AJ, LaCava S, Mehta M, Schiff D, Thandoni A, Jhawar S, Danish S, Haffty BG and Chen S: The glutamate release inhibitor riluzole increases DNA damage and enhances cytotoxicity in human glioma cells, in vitro and in vivo. Oncotarget 10 : 2824-2834, 2019.

8. Dolfi SC, Medina DJ, Kareddula A, Paratala B, Rose A, Dhami J, Chen S, Ganesan S, Mackay G, Vazquez A and Hirshfield KM: Riluzole exerts distinct antitumor effects from a metabotropic glutamate receptor 1-specific inhibitor on breast cancer cells. Oncotarget 8: 44639-44653, 2017.

9. Prickett TD and Samuels Y: Molecular pathways: Dysregulated glutamatergic signaling pathways in cancer. Clin Cancer Res 18 4240-4246, 2012.

10. Skerry TM and Genever PG: Glutamate signalling in non-neuronal tissues. Trends Pharmacol Sci 22: 174-181, 2001.

11. Hinoi E, Takarada T, Ueshima T, Tsuchihashi Y and Yoneda Y: Glutamate signaling in peripheral tissues. Eur J Biochem 271: $1-13,2004$.

12. Cowan RW, Seidlitz EP and Singh G: Glutamate signaling in healthy and diseased bone. Front Endocrinol (Lausanne) 3: 89, 2012.

13. Hollmann $\mathrm{M}$ and Heinemann S: Cloned glutamate receptors. Annu Rev Neurosci 17: 31-108, 1994.

14. Reiner A and Levitz J: Glutamatergic signaling in the central nervous system: Ionotropic and metabotropic receptors in concert. Neuron 98: 1080-1098, 2018

15. Lin W, Wang C, Liu G, Bi C, Wang X, Zhou Q and Jin $H$ : SLC7A11/xCT in cancer: Biological functions and therapeutic implications. Am J Cancer Res 10: 3106-3126, 2020.

16. Muir A, Danai LV, Gui DY, Waingarten CY, Lewis CA and Vander Heiden MG: Environmental cystine drives glutamine anaplerosis and sensitizes cancer cells to glutaminase inhibition. Elife 6: e27713, 2017.

17. Sharma MK, Seidlitz EP and Singh G: Cancer cells release glutamate via the cystine/glutamate antiporter. Biochem Biophys Res Commun 391: 91-95, 2010.

18. Ye ZC, Rothstein JD and Sontheimer H: Compromised glutamate transport in human glioma cells: Reduction-mislocalization of sodium-dependent glutamate transporters and enhanced activity of cystine-glutamate exchange. J Neurosci 19: 10767-10777, 1999

19. Ye ZC and Sontheimer H: Glioma cells release excitotoxic concentrations of glutamate. Cancer Res 59: 4383-4391, 1999.

20. Savaskan NE, Heckel A, Hahnen E, Engelhorn T, Doerfler A Ganslandt O, Nimsky C, Buchfelder M and Eyüpoglu IY: Small interfering RNA-mediated $\mathrm{xCT}$ silencing in gliomas inhibits neurodegeneration and alleviates brain edema. Nat Med 14 629-632, 2008

21. Shin SS, Jeong BS, Wall BA, Li J, Shan NL, Wen Y, Goydos JS and Chen S: Participation of $\mathrm{xCT}$ in melanoma cell proliferation in vitro and tumorigenesis in vivo. Oncogenesis 7: 86, 2018.

22. Wangpaichitr M, Wu C, Li YY, Nguyen DJM, Kandemir H, Shah S, Chen S, Feun LG, Prince JS, Kuo MT and Savaraj N: Exploiting ROS and metabolic differences to kill cisplatin resistant lung cancer. Oncotarget 8: 49275-49292, 2017.

23. Martin GS: Cell signaling and cancer. Cancer Cell 4: 167-174, 2003.

24. Hemmings BA and Restuccia DF: PI3K-PKB/Akt pathway. Cold Spring Harb Perspect Biol 4: a011189, 2012.

25. Nicholson KM and Anderson NG: The protein kinase B/Akt signalling pathway in human malignancy. Cell Signal 14: 381-395, 2002 .

26. Schmelzle T and Hall MN: TOR, a central controller of cell growth. Cell 103: 253-262, 2000.

27. Sanchez-Vega F, Mina M, Armenia J, Chatila WK, Luna A, La KC, Dimitriadoy S, Liu DL, Kantheti HS, Saghafinia S, et al: Oncogenic signaling pathways in the cancer genome atlas. Cell 173: 321-337.e10, 2018

28. Namkoong J, Shin SS, Lee HJ, Marin YE, Wall BA, Goydos JS and Chen S: Metabotropic glutamate receptor 1 and glutamate signaling in human melanoma. Cancer Res 67: 2298-2305, 2007.
29. Choi KY, Chang K, Pickel JM, Badger JD II and Roche KW: Expression of the metabotropic glutamate receptor 5 (mGluR5) induces melanoma in transgenic mice. Proc Natl Acad Sci USA 108: 15219-15224, 2011

30. Prickett TD, Wei X, Cardenas-Navia I, Teer JK, Lin JC, Walia V, Gartner J, Jiang J, Cherukuri PF, Molinolo A, et al: Exon capture analysis of $\mathrm{G}$ protein-coupled receptors identifies activating mutations in GRM3 in melanoma. Nat Genet 43: 1119-1126, 2011.

31. Yip D, Le MN, Chan JL, Lee JH, Mehnert JA, Yudd A, Kempf J, Shih WJ, Chen S and Goydos JS: A phase 0 trial of riluzole in patients with resectable stage III and IV melanoma. Clin Cancer Res 15: 3896-3902, 2009.

32. Rosenberg SA, Niglio SA, Salehomoum N, Chan JL, Jeong BS, Wen Y, Li J, Fukui J, Chen S, Shin SS and Goydos JS: Targeting glutamatergic signaling and the PI3 kinase pathway to halt melanoma progression. Transl Oncol 8: 1-9, 2015.

33. Sperling S, Aung T, Martin S, Rohde V and Ninkovic M Riluzole: A potential therapeutic intervention in human brain tumor stem-like cells. Oncotarget 8: 96697-96709, 2017

34. Rajendran G, Shanmuganandam K, Bendre A, Muzumdar D, Goel A and Shiras A: Epigenetic regulation of DNA methyltransferases: DNMT1 and DNMT3B in gliomas. J Neurooncol 104: 483-494, 2011.

35. Liao S, Ruiz Y, Gulzar H, Yelskaya Z, Ait Taouit L, Houssou M, Jaikaran T, Schvarts Y, Kozlitina K, Basu-Roy U, et al: Osteosarcoma cell proliferation and survival requires mGluR5 receptor activity and is blocked by Riluzole. PLoS One 12: e0171256, 2017

36. Nusse $\mathrm{R}$ and Clevers $\mathrm{H}$ : Wnt/ $\beta$-catenin signaling, disease, and emerging therapeutic modalities. Cell 169: 985-999, 2017

37. Kageshita T, Hamby CV, Ishihara T, Matsumoto K, Saida T and Ono T: Loss of beta-catenin expression associated with disease progression in malignant melanoma. Br J Dermatol 145: 210-216, 2001.

38. Biechele TL, Camp ND, Fass DM, Kulikauskas RM, Robin NC, White BD, Taraska CM, Moore EC, Muster J, Karmacharya R, et al: Chemical-genetic screen identifies riluzole as an enhancer of $\mathrm{Wnt} / \beta$-catenin signaling in melanoma. Chem Biol 17: 1177-1182, 2010.

39. Duchen MR: Mitochondria and calcium: From cell signalling to cell death. J Physiol 529 Pt 1: 57-68, 2000.

40. Beltran-Parrazal L and Charles A: Riluzole inhibits spontaneous $\mathrm{Ca}^{+}$signaling in neuroendocrine cells by activation of $\mathrm{K}+$ channels and inhibition of $\mathrm{Na}^{+}$channels. Br J Pharmacol 140: 881-888, 2003.

41. Hemendinger RA, Armstrong EJ III, Radio N and Brooks BR Neurotoxic injury pathways in differentiated mouse motor neuron-neuroblastoma hybrid (NSC-34D) cells in vitro-limited effect of riluzole on thapsigargin, but not staurosporine, hydrogen peroxide and homocysteine neurotoxicity. Toxicol Appl Pharmacol 258: 208-215, 2012.

42. Kamal T, Green TN, Morel-Kopp MC, Ward CM, McGregor AL, McGlashan SR, Bohlander SK, Browett PJ, Teague L, During MJ, et al: Inhibition of glutamate regulated calcium entry into leukemic megakaryoblasts reduces cell proliferation and supports differentiation. Cell Signal 27: 1860-1872, 2015.

43. Jan CR, Lu YC, Jiann BP, Chang HT and Huang JK: Effect of riluzole on cytosolic $\mathrm{Ca}_{2}{ }^{+}$increase in human osteosarcoma cells. Pharmacology 66: 120-127, 2002.

44. Wadosky KM, Shourideh M, Goodrich DW and Koochekpour S Riluzole induces AR degradation via endoplasmic reticulum stress pathway in androgen-dependent and castration-resistant prostate cancer cells. Prostate 79: 140-150, 2019.

45. Liou GY and Storz P: Reactive oxygen species in cancer. Free Radic Res 44: 479-496, 2010.

46. Pelicano H, Carney D and Huang P: ROS stress in cancer cells and therapeutic implications. Drug Resist Updat 7: 97-110, 2004.

47. Chakravarthi S, Jessop CE and Bulleid NJ: The role of glutathione in disulphide bond formation and endoplasmic-reticulum-generated oxidative stress. EMBO Rep 7: 271-275, 2006.

48. Janáky R, Ogita K, Pasqualotto BA, Bains JS, Oja SS, Yoneda Y and Shaw CA: Glutathione and signal transduction in the mammalian CNS. J Neurochem 73: 889-902, 1999.

49. Cao SS and Kaufman RJ: Endoplasmic reticulum stress and oxidative stress in cell fate decision and human disease. Antioxid Redox Signal 21: 396-413, 2014

50. Hayes JD, Dinkova-Kostova AT and Tew KD: Oxidative stress in cancer. Cancer Cell 38: 167-197, 2020.

51. Kennedy L, Sandhu JK, Harper ME and Cuperlovic-Culf M: Role of glutathione in cancer: From mechanisms to therapies. Biomolecules 10: 1429, 2020 
52. Seol HS, Lee SE, Song JS, Lee HY, Park S, Kim I, Singh SR, Chang S and Jang SJ: Glutamate release inhibitor, Riluzole, inhibited proliferation of human hepatocellular carcinoma cells by elevated ROS production. Cancer Lett 382: 157-165, 2016.

53. Wall BA, Wangari-Talbot J, Shin SS, Schiff D, Sierra J, Yu LJ, Khan A, Haffty B, Goydos JS and Chen S: Disruption of GRM1-mediated signalling using riluzole results in DNA damage in melanoma cells. Pigment Cell Melanoma Res 27: 263-274, 2014

54. Cerchio R Jr, Marinaro C, Foo TK, Xia B and Chen S: Nonhomologous end-joining repair is likely involved in the repair of double-stranded DNA breaks induced by riluzole in melanoma cells. Melanoma Res 30: 303-308, 2020.

55. Raghubir M, Azeem SM, Hasnat R, Rahman CN, Wong L, Yan S Huang YQ, Zhagui R, Blyufer A, Tariq I, et al: Riluzole-induced apoptosis in osteosarcoma is mediated through Yes-associated protein upon phosphorylation by c-Abl Kinase. Sci Rep 11: 20974 2021.

56. Jo OD, Martin J, Bernath A, Masri J, Lichtenstein A and Gera J: Heterogeneous nuclear ribonucleoprotein A1 regulates cyclin D1 and c-myc internal ribosome entry site function through Akt signaling. J Biol Chem 283: 23274-23287, 2008.

57. Benavides-Serrato A, Saunders JT, Holmes B, Nishimura RN, Lichtenstein A and Gera J: Repurposing potential of Riluzole as an ITAF Inhibitor in mTOR therapy resistant glioblastoma. Int J Mol Sci 21: 344, 2020.

58. Basu AK: DNA Damage, mutagenesis and cancer. Int J Mol Sci 19: 970, 2018

59. O'Connor MJ: Targeting the DNA damage response in cancer. Mol Cell 60: 547-560, 2015.

60. Srinivas US, Tan BWQ, Vellayappan BA and Jeyasekharan AD ROS and the DNA damage response in cancer. Redox Biol 25 101084, 2019.

61. Mehnert JM, Silk AW, Lee JH, Dudek L, Jeong BS, Li J, Schenkel JM, Sadimin E, Kane M, Lin H, et al: A phase II trial of riluzole, an antagonist of metabotropic glutamate receptor 1 (GRM1) signaling, in patients with advanced melanoma. Pigment Cell Melanoma Res 31: 534-540, 2018.

62. Wall BA, Yu LJ, Khan A, Haffty B, Goydos JS and Chen S: Riluzole is a radio-sensitizing agent in an in vivo model of brain metastasis derived from GRM1 expressing human melanoma cells. Pigment Cell Melanoma Res 28: 105-109, 2015.

63. Lemieszek M, Stepulak A, Sawa-Wejksza K, Czerwonka A, Ikonomidou C and Rzeski W: Riluzole inhibits proliferation, migration and cell cycle progression and induces apoptosis in tumor cells of various origins. Anticancer Agents Med Chem 18: 565-572, 2018

64. Sun L, Wu C, Ming J, Nie X, Guo E, Zhang W and Hu G: Riluzole enhances the response of human nasopharyngeal carcinoma cells to ionizing radiation via ATM/P53 signalling pathway. J Cancer 11: 3089-3098, 2020.

65. Yun CW and Lee SH: The roles of autophagy in cancer. Int J Mol Sci 19: 3466, 2018.

66. Linder B and Kögel D: Autophagy in cancer cell death. Biology (Basel) 8: 82, 2019.

67. Sun R, He X, Jiang X and Tao H: The new role of riluzole in the treatment of pancreatic cancer through the apoptosis and autophagy pathways. J Cell Biochem: Nov 11, 2019 (Epub ahead of print).

68. Carneiro BA and El-Deiry WS: Targeting apoptosis in cancer therapy. Nat Rev Clin Oncol 17: 395-417, 2020

69. Le MN, Chan JL, Rosenberg SA, Nabatian AS, Merrigan KT, Cohen-Solal KA and Goydos JS: The glutamate release inhibitor Riluzole decreases migration, invasion, and proliferation of melanoma cells. J Invest Dermatol 130: 2240-2249, 2010.

70. Khan AJ, Wall B, Ahlawat S, Green C, Schiff D, Mehnert JM, Goydos JS, Chen S and Haffty BG: Riluzole enhances ionizing radiation-induced cytotoxicity in human melanoma cells that ectopically express metabotropic glutamate receptor 1 in vitro and in vivo. Clin Cancer Res 17: 1807-1814, 2011.

71. Akamatsu K, Shibata MA, Ito Y, Sohma Y, Azuma H and Otsuki Y: Riluzole induces apoptotic cell death in human prostate cancer cells via endoplasmic reticulum stress. Anticancer Res 29: 2195-2204, 2009.

72. Raghubir M, Rahman CN, Fang J, Matsui H and Mahajan SS Osteosarcoma growth suppression by riluzole delivery via iron oxide nanocage in nude mice. Oncol Rep 43: 169-176, 2020.

73. Rampersaud S, Fang J, Wei Z, Fabijanic K, Silver S, Jaikaran T, Ruiz Y, Houssou M, Yin Z, Zheng S, et al: The effect of cage shape on nanoparticle-based drug carriers: Anticancer drug release and efficacy via receptor blockade using dextran-coated iron oxide nanocages. Nano Lett 16: 7357-7363, 2016.
74. Bayat Mokhtari R, Homayouni TS, Baluch N, Morgatskaya E, Kumar S, Das B and Yeger H: Combination therapy in combating cancer. Oncotarget 8: 38022-38043, 2017.

75. Pucci C, Martinelli C and Ciofani G: Innovative approaches for cancer treatment: Current perspectives and new challenges. Ecancermedicalscience 13: 961, 2019.

76. Falzone L, Salomone S and Libra M: Evolution of cancer pharmacological treatments at the turn of the Third Millennium. Front Pharmacol 9: 1300, 2018.

77. Fortunato A: The role of hERG1 ion channels in epithelial-mesenchymal transition and the capacity of riluzole to reduce cisplatin resistance in colorectal cancer cells. Cell Oncol (Dordr) 40 367-378, 2017.

78. Lee HJ, Wall BA, Wangari-Talbot J, Shin SS, Rosenberg S, Chan JL, Namkoong J, Goydos JS and Chen S: Glutamatergic pathway targeting in melanoma: single-agent and combinatorial therapies. Clin Cancer Res 17: 7080-7092, 2011.

79. Speyer CL, Bukhsh MA, Jafry WS, Sexton RE, Bandyopadhyay S and Gorski DH: Riluzole synergizes with paclitaxel to inhibit cell growth and induce apoptosis in triple-negative breast cancer. Breast Cancer Res Treat 166: 407-419, 2017.

80. Lacomblez L, Bensimon G, Leigh PN, Guillet P and Meininger V: Dose-ranging study of riluzole in amyotrophic lateral sclerosis. Amyotrophic Lateral Sclerosis/Riluzole Study Group II Lancet 347: 1425-1431, 1996.

81. Groeneveld GJ, Van Kan HJ, Kalmijn S, Veldink JH, Guchelaar HJ, Wokke JH and Van den Berg LH: Riluzole serum concentrations in patients with ALS: Associations with side effects and symptoms. Neurology 61: 1141-1143, 2003.

82. Groeneveld GJ, van Kan HJ, Lie-A-Huen L, Guchelaar HJ and van den Berg LH: An association study of riluzole serum concentration and survival and disease progression in patients with ALS. Clin Pharmacol Ther 83: 718-722, 2008.

83. Le Liboux A, Cachia JP, Kirkesseli S, Gautier JY, Guimart C Montay G, Peeters PA, Groen E, Jonkman JH and Wemer J: A comparison of the pharmacokinetics and tolerability of riluzole after repeat dose administration in healthy elderly and young volunteers. J Clin Pharmacol 39: 480-486, 1999.

84. Bellingham MC: A review of the neural mechanisms of action and clinical efficiency of riluzole in treating amyotrophic lateral sclerosis: What have we learned in the last decade? CNS Neurosci Ther 17: 4-31, 2011.

85. Wokke J: Riluzole. Lancet 348: 795-799, 1996

86. Miller RG, Mitchell JD, Lyon M and Moore DH: Riluzole for amyotrophic lateral sclerosis (ALS)/motor neuron disease (MND). Amyotroph Lateral Scler Other Motor Neuron Disord 4: 191-206, 2003

87. Grant P, Song JY and Swedo SE: Review of the use of the glutamate antagonist riluzole in psychiatric disorders and a description of recent use in childhood obsessive-compulsive disorder. J Child Adolesc Psychopharmacol 20: 309-315, 2010.

88. Sorenson EJ: An acute, life-threatening, hypersensitivity reaction to riluzole. Neurology 67: 2260-2261, 2006.

89. Inoue-Shibui A, Kato M, Suzuki N, Kobayashi J, Takai Y, Izumi R, Kawauchi Y, Kuroda H, Warita H and Aoki M: Interstitial pneumonia and other adverse events in riluzole-administered amyotrophic lateral sclerosis patients: A retrospective observational study. BMC Neurol 19: 72, 2019.

90. Lacomblez L, Bensimon G, Leigh PN, Debove C, Bejuit R, Truffinet P and Meininger V; ALS Study Groups I and II: Long-term safety of riluzole in amyotrophic lateral sclerosis. Amyotroph Lateral Scler Other Motor Neuron Disord 3: 23-29, 2002.

91. Speyer CL, Nassar MA, Hachem AH, Bukhsh MA, Jafry WS, Khansa RM and Gorski DH: Riluzole mediates anti-tumor properties in breast cancer cells independent of metabotropic glutamate receptor-1. Breast Cancer Res Treat 157: 217-228, 2016.

92. Poupon L, Lamoine S, Pereira V, Barriere DA, Lolignier S, Giraudet F, Aissouni Y, Meleine M, Prival L, Richard D, et al: Targeting the TREK-1 potassium channel via riluzole to eliminate the neuropathic and depressive-like effects of oxaliplatin. Neuropharmacology 140: 43-61, 2018.

93. Yamada T, Tsuji S, Nakamura S, Egashira Y, Shimazawa M, Nakayama N, Yano H, Iwama T and Hara H: Riluzole enhances the antitumor effects of temozolomide via suppression of MGMT expression in glioblastoma. J Neurosurg 134: 701-710, 2020.

This work is licensed under a Creative Commons Attribution-NonCommercial-NoDerivatives 4.0 International (CC BY-NC-ND 4.0) License. 